International Journal of Computer Science \& Information Technology (IJCSIT) Vol 4, No 1, Feb 2012

\title{
A QUALITATIVE STUDY OF LP-ITS: LINEAR Programming InTElligent Tutoring System
}

\author{
Samy S. Abu Naser \\ Faculty of Engineering and Information technology, Al-Azhar University-Gaza, \\ Palestine. \\ samy@abunasser. com
}

\begin{abstract}
This paper is an attempt to evaluate the Linear Programming Intelligent Tutoring System on the basis of perspective and experiences of instructors and students who used the system in the Faculty of Engineering \& Information Technology at Al-Azhar University in Gaza. A phenomenological method, with a focal point group was used. The first objective of this study was to discuss the important aspects of the design and development of LP-ITS. The second was to evaluate LP-ITS on the basis of instructors and students experiences. The third was to explore the perspectives of students and instructors about the implication of LP-ITS skills in lecture hall situations. The results were discussed in terms of the evaluation of the LP-ITS and its implications for learning and teaching activities in the lecture hall.
\end{abstract}

\section{KEYWORDS}

Evaluation of Tutors, Intelligent Tutoring Systems, e-learning systems, AI in Education.

\section{INTRODUCTION}

It has been observed that the leading paradigm for previous research has usually been that of the quantitative assessment of Intelligent Tutoring Systems (ITS) research. However, there has been an increasing interest in the use of qualitative approaches to study instructors and students experiences and perspectives of ITS $[8,9,10,18,19,20]$. Researchers are more concerned with the qualitative studies, connecting an interpretive method to its subject issue to provide a detailed explanation of a particular condition or setting in a particular lecture hall or institution. The main words in qualitative research are difficulty, appropriateness, discovery, and inductive sense. Many diverse categories of research are appropriate to be trained in education like ethnographic cram, case studies, grounded assumption, participative inquisition, and phenomenological study $[8,9,10]$. Interpretive method such as phenomenology concentrate on understanding the nature of actuality throughout people's knowledge using subjectively building procedures and connotations. It has a tendency to produce an epistemology where phenomena have delineate actualities. Phenomenological method accentuates the subjective procedures of the situation. The objective of this method is to find out what a knowledge means for those who have had the knowledge and are capable to present a complete explanation of it. This method is remarkable in ways in which a phenomenon is practised, more willingly than in the temperament of the phenomenon itself $[8,10,11,12]$. Although the instructors and students were involved in the implementation of ITS, there have been no attempts made to explore their experience of such systems.

DOI : $10.5121 /$ ijcsit.2012.4116 
With these issues in mind, instructor and student experiences to evaluate ITS were used to guide decisions on methodology and data collection of this study. In this context, this study required an interpretive approach, which, in turn, required close collaboration with the instructors and students, a common agenda in order to understand instructor and student ITS experiences. The interpretive idea highlights that experience are formulated by people vigorously participating in the research technique, and that researchers try to comprehend the experience from the viewpoint of those who have had the experience. It also highlights that research is an artefact of the morals of researchers and contributors and cannot be quite apart from them. Consequently, we captured the ontological postulation linked with interpretive concept that manifold realities exist in instructor and student experiences in terms of the ITS. We chose to carry out this study using qualitative methods from the phenomenological point of view so that we can gain an understanding of the experience obtained by instructors and students in the context of the ITS.

From the phenomenological point of view, this research is devoted to a study of instructor and student direct experiences in the ITS; and the researchers of this study sees behavior as determined by the phenomena of instructor and student experiences rather than by external, objective, and physically described reality $[1,3,4,5]$. We built this research on the ground that the experiences and perspectives of institution instructors are an essential source in offering an adequate assessment of the ITS, not only for rising the quantity of ITS instructors, but also of ITS students in addition.

The phenomenon of our interest in this research was to explore university instructor and student perspectives and evaluation on the ITS in the Faculty of Engineering and Information Technology setting in Gaza, Palestine. The participants in this study constituted the instructors and students who were interviewed. We used face-to-face, semi-structured interviews to select 3 instructors and 18 students to form focal point groups. Focal point group was the most proper research means due to the concentrated nature of the research matter. This form of qualitative research presented the advantages of concentrating on the definite experience and assessment of instructors and students on the ITS. An analysis of the data from the perspective of the phenomenological paradigm was performed. The intention of this approach was to achieve an understanding of the circumstances from the perspective of contributors and within ITS awareness and subjectivity.

This study can provide clear insight in terms of instructor and student perspectives on ITS especially through studying the distinctive experience of them. Due to the fact that the approach is affected by the subjectivity of phenomena of instructors and students, this type of research offers studying the temperament and substance of such phenomena, in particular from the temperament of instructor and student reality as a way of understanding the instructor and student own lived experiences. With proper and deeper understanding about ITS, instructors, students, educators and policy makers may be able to consider contextual influences in designing and applying ITS. By understanding more thoroughly the instructors and students reality on ITS, universities may implement more effective systems to better prepare instructors and their students to study efficiently and provide them with better access to teaching facilities and give enough support to enable a better teaching and learning environment.

The remaining of the paper consists of four sections. 
International Journal of Computer Science \& Information Technology (IJCSIT) Vol 4, No 1, Feb 2012

$\circ$ The first is a background of the Linear Programming Intelligent Tutoring System design.

- The second is an explanation of the technique and the procedures employed in this research.

○ The third part states the results obtained from analyzing the data.

- The forth is the conclusion derived from the results of this research.

\section{RELATED WORK}

A literature search showed that although much of the work on evaluation of Intelligent tutoring systems is on the measurement with different constructs by quantitative studies $([1,2,3,4,5,6$, 7], no qualitative research has so far attempted to explore the experience of instructors and students about ITS.

From the literature review, it can be seen that much of what is known about Intelligent Tutoring Systems evaluation has been generated by studies based on quantitative evaluation. The perceptions and evaluations of instructors and students on ITS have not yet been explored in depth.

\section{Linear Programming Intelligent Tutoring System Design}

An Intelligent Tutoring System for teaching linear programming called LP-ITS have been developed to students enrolled in Operations Research in the faculty of Engineering and Information Technology at Al-Azhar University in Gaza. LP-ITS gradually introduces students to the concept of Linear Programming and automatically generates problems for the students to solve. The key sections that draws the main structure of the tutoring material are:

1. Understand basic assumptions and properties of Linear Programming (LP),

2. General LP notation,

3. LP formulation of the model,

4. Minimization and Maximization Problems,

5. Graphical solution of LP,

6. The Simplex Algorithm

7. The M Method

8. Special Cases of LP

9. Sensitivity Analysis 
International Journal of Computer Science \& Information Technology (IJCSIT) Vol 4, No 1, Feb 2012

The design of the LP-ITS required two factors to be considered: the student and the instructor requirements. In order for an Intelligent Tutoring System to be successful in today's e-learning society, LP-ITS was designed with the following qualities.

\subsection{Student Requirements}

The following properties were very important in the design of LP-ITS to satisfy the students needs:

○ Provide an intelligent user-friendly interface that make available all the necessary features for efficient Intelligent tutoring System;

- LP-ITS can be used as single used or multi-user environment ;

- Process student's answer and respond swiftly to the student;

- Provide the proper communication skills with the user in terms of hint and error messages;

○ Keep track of the student performance in a database; and

- Module the user during the solution of the problem.

\subsection{Instructor Requirements}

The following factors were considered important in meeting the needs of teachers using this LP-ITS:

- The teacher is not required to author the problem; but to classify the level of difficulty of linear programming problems;

- The teacher is not asked to supply the solution of the problem because the LP-ITS find the solution in its own;

- LP-ITS must be able to monitor the student while he is solving the problem because the students can solve the problem in many different ways;

- Information about student performance should be available and accessible any time;

- A user friendly interface to enter the classification of problems and level of difficulty.

\subsection{LP-ITS User Interface}

The main user interface for the LP-ITS has been designed cautiously to fulfil the requirements of the students and instructor and it is written in Java language. Figure 1 present the user interface of the linear programming tutor that consists of icons and drop down menus. 


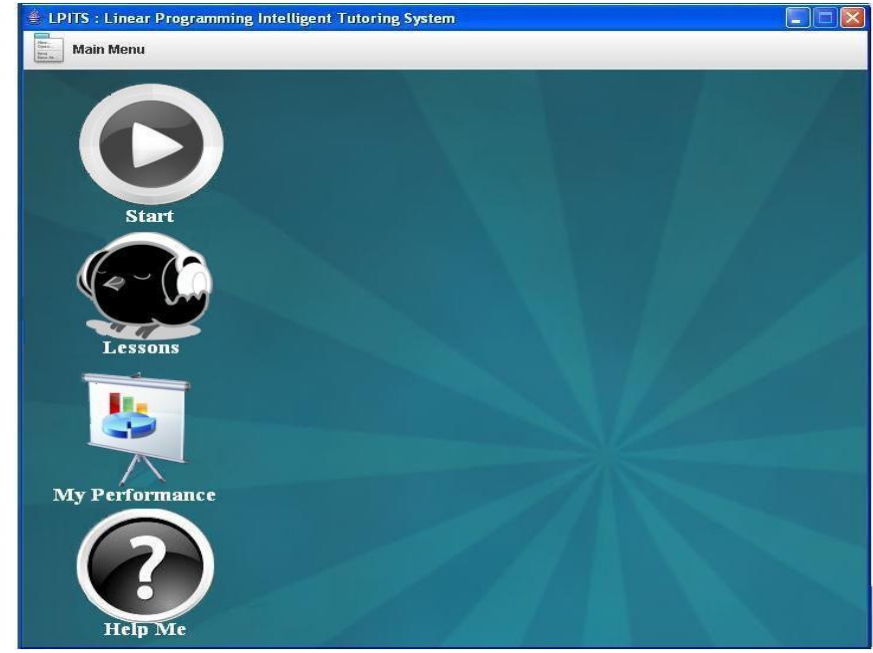

Figure 1: LP-ITS main user interface

\section{METHODOLOGY AND PROCEDURES}

\subsection{Participants}

Students enrolled in operations research course during the fall of 2010 in the Faculty of Engineering and Information Technology at Al Azhar University, Gaza, and instructors who have knowledge or taught operations research. The total number of students participated in this study was 120 students. The 120 students divided into 3 sections. Two sections were for male students and the third for females. Each section has 40 students and one instructor. A focal point group of 21 participant ware selected out of the population of this study. The focal point group consisted of 18 students (12 males and 6 females) and 3 instructors.

\subsection{Materials and Procedures}

An operation research course equipped with LP-ITS tutor was given to the whole population of the study during the fall of 2010 in order to collect experiences and perspectives of the instructors and students. The instructors and students spent a complete semester three hours per week attending the course that consisted of theoretical and practical section put together, to assess this course along with their experiences with a phenomenological approach, with a focal point group method.

\subsection{Evaluation of the course}

Evaluation was viewed as a combination of learning and teaching process. The students and instructors therefore, evaluated how worthwhile the activities and learning experiences on operation research with LP-ITS tutor were, and their implications to the learning and the teaching processes. These evaluations of the students and instructors were documented through interviews that were held at the end of the course.

\subsection{Focal point group interview}

At the end of the course, a set of semi-structured group interviews with the students and instructors who participated in the course were performed by the researchers to gather data for this research. We did not use individual interview, rather, we utilized focal point groups to gather each students and instructor own perspectives in a more in-depth manner. In addition, the 
International Journal of Computer Science \& Information Technology (IJCSIT) Vol 4, No 1, Feb 2012

instructors and students did not have sufficient time to be interviewed separately, this approach also contributed to save time whilst escalating the effectiveness through group interaction.

Interviews are best performed by the end of the study, however, instead of at the beginning, as they have a tendency to form answers to the researchers' perceptions of how things are $[9,13]$. A focal point group is a semi structured manner of group interviewing invented to give way contextually prosperous information about a subject in an efficient and rapid style. Focal point group is particularly useful in monitoring studies, in needs assessments, and course evaluations, which provide an exploratory approach and may be more effective in certain research processes than the more traditional ones. In comparison to an individual interview:

1. A greater extent of information can be composed in shorter and more well-organized time periods.

2. The focal point group provides way in to gather experience and communication of Participants on subjects that are not easy to observe or exceptional in occurrence.

3. Focal point group can offer several options at a variety of steps of the research process, from hypothesis creation to hypothesis testing $[8,9,10,11,12]$.

To be consistent with the above authors, focal point group was selected as a means to gather data of this research owing to its advantages associated to the nature of this study.

Due to the fact that focal point group method requires that participants be together, rather than the groups forming by themselves, the students' and instructors' experiences are written down in an unusual circumstances. Maybe one of the most exciting aspects of dealing with focal point groups is that, as yet, there are no clear-cut regulations in using focal point groups. To be consistent with the ideas of above-mention authors, A careful thought was given to the development of the questions to be offered to the focal point group. Therefore, questions presented to group participants were open-ended so as to let participants to deal with the issues from a variety of points of views and magnitude. We constructed an interview guide, which consisted of 10 questions (see Appendix 1) for the evaluation of the operation research course with the LP-ITS. This interview guide was helpful in making certain that the focal point on main points was not misplaced and the vital appropriate questions were asked during the group meetings, therefore serving as an outline of the focal point groups. Before starting the interview, we asked students and instructors for their readiness to take part in the interview session and their intent to contribute part of their time and input to a focal point group doings. All participants were enthusiastic to participate in the interview. Every participant was given an interview guide and was told about the its contents. They were also informed that any conclusion coming out of the interviews would be reserved in full discretion.

At end, we had to tackle the question of how to assemble the focal point groups, as well as settle on how many groups is required. In order to comprise a focal point group study consistent with the above-mention recommendation, we decided that inter group heterogeneity and intra-group homogeneity with regard to students, instructors and gender; a total of three focal point groups were formed, each with seven participants. Interviews lasted approximately 120 minutes with the three groups, each group taking 40 minutes approximately.

The focal point groups were led by the researchers, whose main task was to facilitate group discussions [13]. Therefore, we served as the moderator for each focal point group. We outlined the purpose and subjects of the focal point group, asked the questions orally. Participants were also presented with an explanation in terms of suitable ways to answer the 
International Journal of Computer Science \& Information Technology (IJCSIT) Vol 4, No 1, Feb 2012

questions and cooperate with others in the group. Notes were taken down during each focal point group interview. Interviews were intended to enable the participant to express their individual perspectives as freely as possible regarding the course phenomenon and to talk spontaneously with the moderator and each participant was also free to supplement additional questions to clarify and probe relevant issues. Precaution was taken not to express, critic, or enforce any effects to the participants in the interview process. All of the three group results were subsequently incorporated into data analysis. While the interview most directly elicited participants' perceptions and evaluations about the course; all parts of the interview helped to yield useful data.

\section{DAta ANALYSIS AND Findings}

The main objective of this study was to investigate perspectives of students and instructors as well as to present information about their perspectives on LP-ITS tutor. Hence, a phenomenological approach and analysis was necessary. A phenomenological approach takes its input from each student and instructor own perspectives of the LP-ITS phenomenon and seeks to identify both similarities and dissimilarities within and between LP-ITS phenomena, with regard to what, how, and why these happen. There are diversity of methods for phenomenological research that are fairly similar in that each entails an inductive thematic course of analysis, in order to attain data $[8,9,11,14,15]$. The interview transcripts were the main supply of data because of length and coverage of the questions. The data was analyzed to classify the categories and themes from the transcripts materials [17]. These steps should not to be conceived as strict policy to be followed but rather be tailored according to the phenomenon of this study and under the condition of the focal point groups.

The transcripts were read over and over to guarantee accuracy of the transcripts of the interviews. Then, each instructor and student responses in the transcripts were coded into categories manually in accordance with the data derived from the interviews of students and instructors. Then, they were divided into subcategories and categories to find out themes. The subcategories were grouped into categories. Then, we examined the relationships between themes and categories, thus forming reporting which were expressive or interpretive. In this manner, we developed various understandings into the phenomena of students and instructors perspectives on LP-ITS tutor under study, such as concepts, causal linkages, and processes. These understandings were used to report to data analysis, through which they were tested and confronted. Iteration thus created an integral part of the research. We analyzed the recorded data in a continuous process of reading over and over to recognize patterns of understanding, while maintaining the reliability of students and instructors perceptions and evaluations. Then related perceptions were grouped together and iteratively contrasted to each other in order to discover similarities and differences among perceptions of students and instructors. The idea behind all these comparisons was to discover perspectives shared by students and instructors.

The collected data were presented using descriptive and interpretive reporting methods $[8,10]$. As shown also in Table 1, twenty five categories under ten themes were derived from the analysis of interview materials. 
International Journal of Computer Science \& Information Technology (IJCSIT) Vol 4, No 1, Feb 2012

Table 1: Themes and categories derived from the analysis of the interview materials

\begin{tabular}{|c|c|c|c|c|c|}
\hline $\begin{array}{c}\mathbf{S N} \\
.\end{array}$ & Category/theme & $\begin{array}{c}\text { No of } \\
\text { Students }\end{array}$ & $\begin{array}{c}\% \text { of } \\
\text { Students }\end{array}$ & $\begin{array}{c}\text { No of } \\
\text { Instructors }\end{array}$ & $\begin{array}{c}\% \text { of } \\
\text { Instructors }\end{array}$ \\
\hline \multirow[t]{3}{*}{ 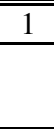 } & "Usefulness of LP-ITS & & & & \\
\hline & Very Useful & 13 & $72.2 \%$ & 2 & $67 \%$ \\
\hline & Useful & 5 & $27.8 \%$ & 1 & $33 \%$ \\
\hline \multirow[t]{4}{*}{2} & LP-ITS satisfy your expectations & & & & \\
\hline & Satisfy my expectation & 14 & $77.77 \%$ & 1 & $33 \%$ \\
\hline & Somewhat Satisfy my expectation & 3 & $16.67 \%$ & 2 & $67 \%$ \\
\hline & Did not satisfy my expectation & 1 & $5.56 \%$ & & \\
\hline \multirow[t]{4}{*}{3} & Benefits from LP-ITS & & & & \\
\hline & Very Beneficial & 16 & $88.88 \%$ & 2 & $67 \%$ \\
\hline & Somewhat beneficial & 1 & $5.56 \%$ & 1 & $33 \%$ \\
\hline & Not beneficial & 1 & $5.56 \%$ & & \\
\hline \multirow[t]{4}{*}{4} & $\begin{array}{l}\text { LP-ITS is better than an ordinary classroom } \\
\text { teaching environment }\end{array}$ & & & & \\
\hline & $\begin{array}{l}\text { Class with LP-ITS is much better than Ordinary } \\
\text { Class without LP-ITS }\end{array}$ & 13 & $72.2 \%$ & 2 & $67 \%$ \\
\hline & $\begin{array}{l}\text { Class with LP-ITS is somewhat better than Ordinary } \\
\text { Class without LP-ITS }\end{array}$ & 4 & $22.22 \%$ & 1 & $33 \%$ \\
\hline & $\begin{array}{l}\text { Class with LP-ITS is much worse than Ordinary } \\
\text { Class without LP-ITS }\end{array}$ & 1 & $5.56 \%$ & & \\
\hline \multirow[t]{4}{*}{5} & $\begin{array}{l}\text { Easiness with which you use and understand } \\
\text { the tutoring style of the LP-ITS }\end{array}$ & & & & \\
\hline & Very Easy to use and understand & 16 & $88.88 \%$ & 3 & $100 \%$ \\
\hline & Somewhat Easy to use and understand & 1 & $5.56 \%$ & & \\
\hline & Very difficult to use and understand & 1 & $5.56 \%$ & & \\
\hline \multirow[t]{4}{*}{6} & Enjoyed LP-ITS & & & & \\
\hline & Very enjoyable & 12 & $66.66 \%$ & 1 & $33 \%$ \\
\hline & Somewhat enjoyable & 5 & $27.8 \%$ & 2 & $67 \%$ \\
\hline & Not enjoyable & 1 & $5.56 \%$ & & \\
\hline \multirow[t]{3}{*}{7} & $\begin{array}{l}\text { Feel you learned more detailed information } \\
\text { in a classroom when using LP-ITS }\end{array}$ & & & & \\
\hline & Very much & 14 & $77.77 \%$ & 1 & $33 \%$ \\
\hline & Little & 4 & $22.22 \%$ & 2 & $67 \%$ \\
\hline \multirow[t]{3}{*}{8} & Feel that LP-ITS is applicable Tutor & & & & \\
\hline & Very applicable & 16 & $88.88 \%$ & 2 & $67 \%$ \\
\hline & To some degree applicable & 2 & $11.11 \%$ & 1 & $33 \%$ \\
\hline \multirow[t]{3}{*}{9} & $\begin{array}{l}\text { Regard the interaction between participants } \\
\text { and LP-ITS }\end{array}$ & & & & \\
\hline & Positive & 8 & $44.44 \%$ & 1 & $33 \%$ \\
\hline & Efficient & 10 & $55.55 \%$ & 2 & $67 \%$ \\
\hline \multirow[t]{3}{*}{10} & $\begin{array}{l}\text { Recommend the development of similar } \\
\text { Intelligent Tutoring System for other } \\
\text { courses }\end{array}$ & & & & \\
\hline & Highly recommend the development & 11 & $61.11 \%$ & 3 & $100 \%$ \\
\hline & Recommend the development & 7 & $38.88 \%$ & & \\
\hline
\end{tabular}


International Journal of Computer Science \& Information Technology (IJCSIT) Vol 4, No 1, Feb 2012

The followings are the explanation of the ten themes along with representative quotations obtained directly from the data, and with interpretation on what the results aimed at.

\section{Usefulness of LP-ITS}

As shown in Table 1, students and instructors held different ideas about the outcomes of the LP-ITS tutor. However, $72 \%$ of the students, 13 out of 18 , shared almost the same view about the usefulness of LP-ITS tutor. Many students stated that they felt LP-ITS was very useful since it is available all the time for them to use. $28 \%$ of the students commented on the usefulness of LP-ITS tutor as useful. On the other hand $66 \%$ and $34 \%$ of instructors said that LP-ITS tutor is very useful and useful respectively.

\section{LP-ITS satisfy your expectations}

$77 \%$ students participating in of this study said that LP-ITS satisfied their expectation while $17 \%$ of the students said that LP-ITS satisfied their expectation to some degree and $6 \%$ of the students were not satisfied with LP-ITS tutor. Some students commented on the feedback method - It gives hints swiftly and to the point. The hints are also not difficult. $33 \%$ and $67 \%$ of the instructors said LP-ITS Tutor satisfied and to some degree satisfied their expectation respectively.

\section{Benefits from LP-ITS}

As shown in Table 1, students and instructors have similar perspective, where they say they benefited form LP-ITS. One student stated that LP-ITS informs me where the error is located exactly so I correct it. One student said that he did not benefit form the LP-ITS.

\section{LP-ITS is better than an ordinary classroom teaching environment}

As shown in Table 1, nearly all students and instructors stated that LP-ITS is better than ordinary class without LP-ITS. One student stated that he is surely learning better in this environment than in an ordinary environment.

\section{Easiness with which you use and understand the tutoring style of the LP-ITS}

Approximately all students and instructors stated that LP-ITS is easy to use and understand. Two students said that if they can have LP-ITS integrated with the operation research course from now and on.

\section{Enjoyed LP-ITS}

All instructors and all students except one said that they enjoyed LP-ITS tutor.

\section{Feel you learned more detailed information in a classroom when using LP-ITS}

As shown in table 1, 14 students out of 18 and one instructor said that they learned more detailed information in a classroom using LP-ITS; however, 4 students and 2 instructors stated that they learned little detailed information.

\section{Feel that LP-ITS is applicable Tutor}


International Journal of Computer Science \& Information Technology (IJCSIT) Vol 4, No 1, Feb 2012

Both instructors and students agree that LP-ITS is applicable Tutor. On students stated that LPITS is very similar to human instructors. Another student said that I felt that I was given more attention by the LP-ITS tutor than the human instructor.

\section{Regard the interaction between participants and LP-ITS}

The students and instructors had similar ideas about the communication and interaction between students with LP-ITS as well as the instructors with LP-ITS. As shown in Table 1, one student reported that communication and interaction between the students and LP-ITS were wonderful, which really was impressing. One instructor shared a related idea and reported it in the following way: "LP-ITS was very affirmative.... I will use it with my students any time I teaches the Operation Research course."

\section{Recommend the development of similar Intelligent Tutoring System for other courses}

As shown in table 1, all students and instructors recommend the development of similar intelligent tutoring systems for other courses.

\section{CONCLUSions}

In this paper an attempt was made to evaluate the Linear Programming Intelligent Tutoring System on the basis of perspective and experiences of instructors and students. A phenomenological approach, with a focal point group method was used. The LP-ITS has been a successful tutor when used with the operations research course. LP-ITS was met with interest by students and instructors alike. After trying several linear programming problems by several groups of students and instructors, they were happy with the performance of LP-ITS. The various comments and improvements raised by students and instructors are being assessed. Amalgamation of some of these asked for features will be presented in the future releases of the Linear Programming Intelligent Tutoring System.

\section{Appendix A}

Interview Guide (Key questions)

Dear Participants,

We are very happy to be with you in Operations Research with LP-ITS tutor. As we mentioned before, here are the open ended key questions that we will ask you in the group interview to identify your experience and perspective related to the course you attended. Your personal information and all specific responses to personalized questions will be not to be disclosed. Thank you for your time and involvement in this study.

Sincerely, 
International Journal of Computer Science \& Information Technology (IJCSIT) Vol 4, No 1, Feb 2012

Open-ended Questions

1. How did you find the usefulness of the Linear Programming Intelligent Tutoring Systems activities and skills in terms of their comprehensibility and their applicability? Why?

2. What are your thoughts in terms of the point to which this LP-ITS would satisfy your expectations? Why?

3. What benefits do you think you are possibly to achieve by participating in this Linear Programming Intelligent Tutoring System? Why?

4. In comparison with a traditional classroom, do you feel LP-ITS is better or worse than an ordinary classroom teaching environment? Why?

5. How do you rate the easiness with which you use and understand the tutoring style of the LPITS? Why?

6. Did you enjoy LP-ITS? Explain why or why not.

7. Do you feel you learn more detailed information or about the same as a regular classroom when using LP-ITS? Explain why or why not.

8. According to your opinion, do you feel that LP-ITS is applicable? Why?

9. How did you regard the interaction between participants and LP-ITS? Why?

10. What is your recommendation and suggestions for the development of similar Intelligent Tutoring System for other courses? Why?

\section{REFERENCES}

[1] Abu Naser S., Evaluating the Effectiveness of the CPP-Tutor, an Intelligent Tutoring system for Students Learning to Program in C++, 2009, Journal of Applied Sciences Research, Vol. 5(1).

[2] Crowley R., Legowski E., Medvedeva O., Tseytlin E., Roh E., and Jukic D., 2007. Evaluation of an Intelligent Tutoring System in Pathology: Effects of External Representation on Performance Gains, Metacognition, and Acceptance. J Am Med Inform Assoc. 2007 MarApr; 14(2): 182-190.

[3] Siddappa, M., Manjunath, A. and Kurian, M., Design, Implementation and Evaluation of Intelligent Tutoring System for Numerical Methods (ITNM). International Conference on Computational Intelligence and Software Engineering, 2009. CiSE 2009, Wuhan.

[4] Andone I. and Sireteanu N, Heuristic Evaluation of Web-Based Intelligent Tutoring Systems. The 4th International Scientific Conference eLSE, Bucharest, April 17-18, 2008.

[5] Jeremic, Z., Jovanovic, J., \& Gasevic, D. (2009). Evaluating an Intelligent Tutoring System for Design Patterns: the DEPTHS Experience. Educational Technology \& Society, 12 (2), 111-130.

[6] Chien T., Yunus A., Ali W., and Bakar A. (2008). The Effect Of An Intelligent Tutoring System (ITS). International Journal of Instruction On Student Achievement In Algebraic Expression. July 2008, Vol.1, No.2. 
International Journal of Computer Science \& Information Technology (IJCSIT) Vol 4, No 1, Feb 2012

[7] Hategekimana C., Gilbert S., Blessing S., Effectiveness of Using an Intelligent Tutoring System to Train Users on. Off-the-Shelf Software., Proceedings of SITE 2008.

[8] Cohen, L., Manion, L., \& Morrison, K. (2011). Research methods in education. London: Routledge Falmer.

[9] Fraenkel, J., Wallen, N. Hyun, H., (2011). How to design and evaluate research in education. 8th edition, Boston: McGraw-Hill Humanities Social.

[10] Mertens, D., (2009). Research methods in education and Psychology: Integrating diversity with quantitative and qualitative approaches. London: Sage Publications, Inc; 3rd edition, 2009.

[11] Pring, R. (2004). Philosophy of educational research. London: Continuum, 2nd edition 2004.

[12] Worthen, B., Sanders, J., \& Fitzpatrick, J., (2010). Program evaluation: Alternative approaches and practical guidelines. Prentice Hall; 4th edition, 2010.

[13] Kvale S. and Brinkman S., 2008. InterViews, 2nd Edition. Thousand Oaks: SAGE. ISBN 9780761925422.

[14] Patton M., 2001. Qualitative Research \& Evaluation Methods, 3rd Edition. Thousand Oaks: SAGE. ISBN 9780761919711.

[15] Lindlof T. and Taylor B., 2010. Qualitative Communication Research Methods, 3rd Edition. Thousand Oaks: SAGE. ISBN-10: 9781412974738.

[16] Creswell, J. (2006), Qualitative Inquiry and Research Design: Choosing Among Five Traditions, 2nd edition. Sage, Thousand Oaks, CA.

[17] Strauss, A. \& Corbin, J. (2007), Basics of Qualitative Research: Techniques and Procedures for Developing Grounded Theory, 3rd edition, Sage, Thousand Oaks.

[18] Denzin N., Lincoln Y. (2011). The SAGE Handbook of Qualitative Research 4th edition, SAGE.

[19] Saldana J.,(2011), Fundamentals of Qualitative Research, Oxford University Press, 2011.

[20] Lapan S., Quartaroli M., Riemer F.., (2011) Qualitative Research: An Introduction to Methods and Designs, Wiley 2011.

\section{Author}

Samy S. Abu Naser was born in Gaza, Palestine, in 1964. He received the B.S. \& M.S. degrees in Computer Science from the University of Western Kentucky, USA in 1987 and 1989 respectively and the Ph.D. degree from North Dakota State University, USA in 1993 in Computer Science. He has been appointed as Associate Professor in Faculty of Engineering and Information Technology, Al-Azhar University, Gaza, Palestine since 2007. He was appointed as Assistant Professor at Al-Azhar University, Gaza, Palestine, 1996-2006. He was appointed as a Teaching Assistant at the University of Kentucky, USA, 1988-1989. He was appointed as a

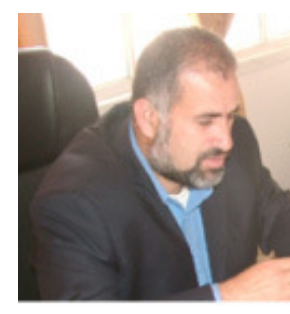
Research Assistant at the North Dakota State University, USA, 1990-1993. He has worked as Field Information Systems Officer at the United Nations Relief and Works Agency(UNRWA), Gaza 19931996. His areas of interest are Artificial Intelligence, Intelligent Tutoring Systems, Expert Systems, Knowledge Management Systems, and Compiler Design. 